\title{
Evaluation of septas in maxillary sinus with cone- beam computed tomography
}

\author{
Nihat Laçin'1@, Bozan Serhat İzol² \\ ${ }^{1}$ İzmir Katip Celebi University, Faculty of Dentistry, Department of Oral and Maxillofacial Surgery, İzmir, Turkey. \\ ${ }^{2}$ Bingöl University, Faculty of Dentistry, Department of Periodontology, Bingöl, Turkey.
}

\section{Correspondence:}

Dr. Nihat Laçin

Izmir Katip Celebi University, Faculty of Dentistry, Department of Oral and Maxillofacial Surgery, Izmir, Turkey.

E-mail:nihat.lacin@hotmail.com

Received: 5 March 2019

Accepted: 24 July 2019

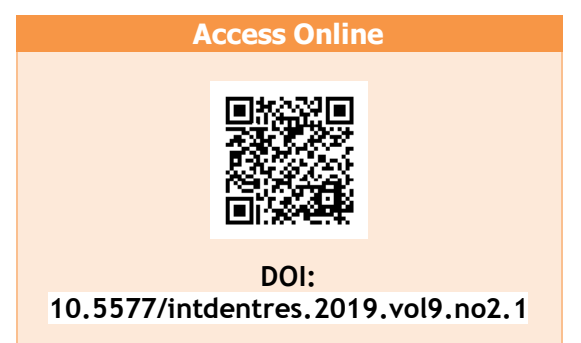

\section{Introduction}

Implant treatment is a prominent and safe restorative methodology speaking to a useful and corrective option. However, its use for the rehabilitation of posterior maxillary regions is usually difficult for the doctor attributable to the decreased bone height. Following tooth loss bone resorption usually starts on the alveolar process of the posterior maxilla. This natural process varies on an individual basis however oftentimes results in volume and density loss and inadequate bone height, which limits the placement of implants of normal length. For this reason, several maxillary sinus lifting methods have been developed to increase the bone height, such as lateral window and transcrestal osteotome techniques (1).

Of these several techniques, sinus lifting with a lateral window approach is that the most often used and has been incontestable to be a reliable and certain procedure for enhancing alveolar bone height within the posterior maxilla (2). Nevertheless, like all surgical intervention, this procedure is also related to many complications, which may compromise the end result of the surgery and the success of the treatment (3). An extensive data of the anatomy and possible variations of the maxillary sinus is thus essential so as to reduce 
the risk of potential complications associated with the procedure (4). Cone beam computed tomography (CBCT) may be a helpful diagnostic tool for providing a comprehensive radiographic assessment before sinus lifting surgery (5).

The cavity of the maxillary sinus is usually divided by septa. The maxillary sinus septa (MSS) are thin structures of maxillary cortical bone. These septa might divide the sinus into two or more compartments $(6,7)$. In 1910, the anatomist Arthur S. Underwood represented the sinus septa as thin fragile and sickleformed walls. The morphology of the maxillary sinus is influenced by the person's age and tooth loss. Edentulous and aged patients show a decreased dimension of the maxillary sinus. With regard to the development of the septa, there are two types of septa; primary septa originate from congenital diversity and secondary septa might develop after the extraction of tooth and irregular pneumatization of the sinus floor (8).

Several studies were conducted on height, location, prevalence, and morphology of the MSSs, in adult patients, using various medical imaging techniques such as CBCT (9). The angle between the septum and the median palatine suture was also assessed by some authors $(10,11)$.

Panoramic radiographs have a poor reliability for diagnosing sinus septa, as shown in several studies (12). To prevent complications during sinus lifting procedures, a detailed preoperative radiographic visualization and examination of the maxillary sinus and related anatomical structures with CBCT has been recommended in recent guidelines. CBCT avoids structural superimposition and image enlargement and distortion, therefore allowing precise 3-dimensional (3D) image and measurement of dental and maxillofacial structures, at a lower radiation dose than traditional computed tomography (CT) (13-19).

The purpose of this study was to examine the frequency, number, location, and orientation of septa in the maxillary sinus based on CBCT imaging. Further, associations between sinus septa and individual patient-related factors (age, sex, and dentition type) were investigated.

\section{Materials and Methods}

In this retrospective study, CBCT scans of 350 patients who visited Izmir Katip Çelebi University, Faculty of Dentistry between January 2012 and December 2017 were evaluated.

Patients consisted of 178 (50.8\%) male and $172(49.14 \%)$ female patients, with a mean age of 32 years (range: 18-65 years). The CBCT scans had been taken for diagnostic purposes as a part of comprehensive evaluation for implant surgery, orthognathic surgery, impacted tooth surgery or orthodontic treatment. As a routine protocol, informed consents were obtained from all patients before exposure. All scans were obtained in supine position, using a NewTom 5G CBCT machine (QR srl, Verona, Italy), operating at $110 \mathrm{kVp}, 1-20 \mathrm{~mA}$ with a $15 \times 12$ field of view (FOV) and standard resolution mode $(0.2 \mathrm{~mm}$ voxel size). Lack of demographic information, images of the maxilla only, radiographic evidence of intraosseous lesions, images of low quality, images without $15 \times 12$ FOV were considered as the exclusion criteria.

The presence of Maxillary sinus septa were detected on NNT station (QR srl, Verona, Italy) using the "zoom" tool and manipulation of brightness and contrast on a computer monitor (The RadiForce MX270W features a 27 -inch large screen size and a 2560 $x 1440$ high-resolution) under dim lighting conditions by an experienced oral and maxillofacial radiologist. CBCT images were evaluated in axial, sagittal, and coronal planes. The maxillary sinus septa were analyzed by considering gender and side (Fig. 1, 2).

$25 \%$ of the CBCT scans were randomly selected and reevaluated by the same investigator 2 weeks after the first evaluation to determine intraexaminer reliability using the intraclass correlation coefficient (ICC).

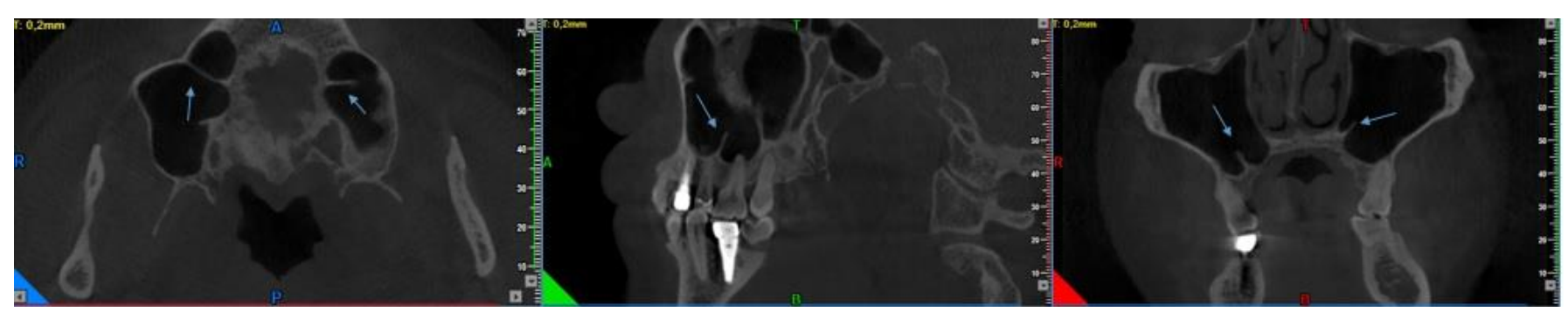

Figure 1. CBCT scans of maxillary sinus septa. Axial,coronal and sagital planes imaging of same patient. Blue arrows show the septas. 


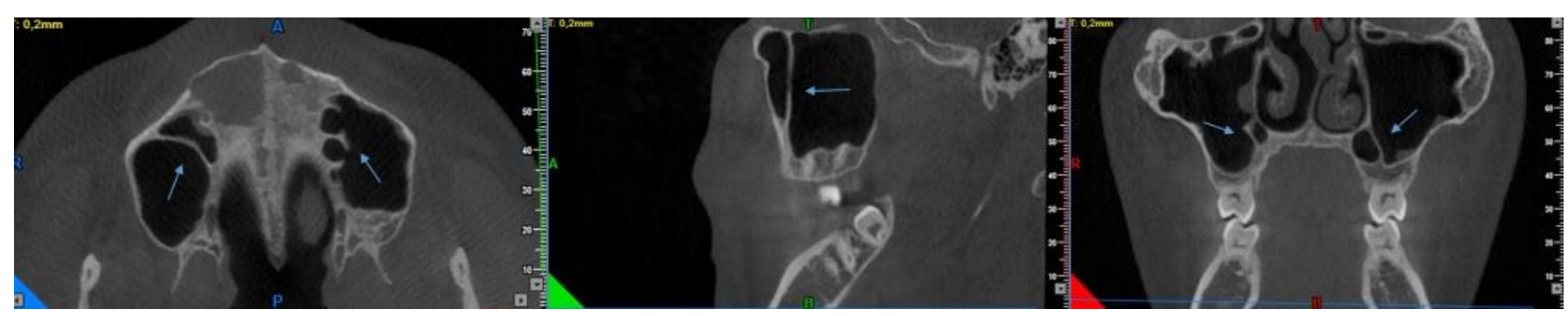

Figure 2. CBCT scans of maxillary sinus septa. Axial,coronal and sagital planes imaging of same patient. Blue arrows show the septas.

\section{Statistical Analysis}

All data analyses were carried out using SigmaStat (version 3.5; Systat Software, San Jose, Calif). The recorded data was statistically analyzed using Chisquare test $(x 2)$ to compare the prevalence of MSS between genders and sides. A probability value of 0.05 or less was set as the significance level.

\section{Results} 0.998).

Intraexaminer reliability was found excellent (ICC:
Maxillary sinus septas (MSSs) were observed in 201 out of 700 sides $(28.71 \%$ ) and in 141 out of 350 patients $(40.28 \%)$. These septas were observed in 70 males and 71 females. Female patients showed higher prevalence $(41.27 \%)$ than the male patients $(39.32 \%)$. But there were not significant differences in the prevalence between gender and sides $(p=0.908)$.

MSSs were also observed in a higher prevalence on the bilateral side $(17.14 \%)$. 45 patients were found to have MSSs on right sides (12.85\%). 36 patients were found to have MSSs on left sides (10.28\%). But there was also no significant difference between right and left sides regardless of gender with respect to the incidence of the MSSs (Table 1).

Table 1. A total of 700 maxillary sinuses of 350 patients were examined(178 male and 172 female)

\begin{tabular}{lccc|}
\hline \multirow{2}{*}{ Gender } & \multicolumn{2}{c}{ Laterality } \\
& Unilateral & Bilateral \\
\hline & Right & Left & \\
\hline Male & 22 & 19 & 29 \\
\hline Female & 23 & 17 & 31 \\
\hline Total & 45 & 36 & 60 \\
\hline
\end{tabular}

Chi- square $=0.192 P=0.908$ no significant difference

\section{Discussion}

Even though the dental implant therapy is quite probable and frequent for treatment of edentulous and partially edentulous patients, additional surgery is usually required because of insufficient bone height in the maxillary posterior region. Indeed, sinus floor elevation may be necessary for placement of implants (20). Nevertheless, anatomical variations within the maxillary sinus have been reported to increase the risk of Schneiderian membrane perforation, and the presence of a sinus septum sometimes becomes the reason of perforation (21). Radiological evaluation is essential to define and find the maxillary sinus septa to lessen preoperative and postoperative complications (21). For preoperative surgical evaluation, CBCT images and panoramic radiographs are commonly used. Nonetheless, some authors reported that panoramic radiography has lots of limitations such as superimposition and magnification (22). So we used CBCT images for this study.

In the present study, we used transverse, axial, and sagittal sections of CBCT images to analyze the 
features of maxillary sinus septa. Septa were observed in $40.28 \%$ of patients and in $28.71 \%$ of maxillary sinuses. The prevalence of septa was $29.7 \%$, in which $30.1 \%$ were females, $29.4 \%$ were males, and $5 \%$ of the patients had multiple septa. Yildirim et al (21) reported that the prevalence of septa was found in $29.7 \%$ of the sinuses using CT imaging, and SaKHDari et al (16) reported that the occurrence rate of septa was $44.8 \%$ in all patients.

An occurrence rate of septa in the left sinus was $36(10.28 \%)$, while in the right sinus was 45 (12.85\%). Velasquez- Plata et al (10) found 72 septa in 312 sinuses, and detected 39 in the left sinus and 36 in the right sinus. Similar to our study, the prevalence of septa was the same at right and left side of patients in recent study. Together, these results suggest that lateralization is not an important factor when evaluating the prevalence of septa. Recent researches showed that the prevalence of septa varied from $25 \%$ to $70 \%(23)$. These differences may be related to the different age of study population and to the differences in radiological imaging technique including $\mathrm{CT}, \mathrm{CBCT}$, and two-dimensional (2D) imaging techniques (panoramic radiograph). Our results did not identify significant differences based on gender, lateralization, and the prevalence of septa. Similar to our work, Yildirim et al (22) found no correlation between sex and the prevalence of septa.

To perform surgical interventions in implant dentistry such as sinus lifting, a profound information of the anatomy of the posterior maxillary region is important $(24,25)$. The majority of septa detected in the present study were complete, and located on the floor of the maxillary sinus in the molar region. This is certainly of clinical significance, as the presence of septa can cause complications during SFE (20). If a sinus septum is not identified prior to the surgical intervention, the preparation or reflection of a hinge door and the elevation of the sinus membrane can be difficult or even impossible during SFE. The most common complication during SFE procedures has been reported to be a perforation of the sinus membrane. In the literature, a frequency of $11 \%$ to $56 \%$ is mentioned for such perforations (26). During SFE procedures, sinus septa have been directly correlated to an increased risk of perforations of the sinus membrane (19). Therefore, clinicians ought to examine the bony anatomy of the maxillary sinus prior to SFE procedures with appropriate radiographic imaging modalities. As panoramic radiographs have a poor reliability for detecting sinus septa,3D radiographic imaging such as CT or CBCT scans have been suggested for proper diagnosis before SFE procedure.

\section{Conclusions}

MSS was observed in $40.28 \%$ of examined Turkish subjects and detected more frequently in females and on the bilateral side. But there was no significant difference between the number of septa and gender, lateralization. Further studies are needed.
Ethical Approval: Ethics committee approval was received for this study from İzmir Katip Çelebi University (No:2019/100).

Peer-review: Externally peer-reviewed.

Author Contributions: Conception N.L., B.S.I.; Design - N.L., B.S.I.; Supervision - N.L.; Materials - N.L., Data Collection and/or Processing-N.L., B.S.I. ; Analysis and/or Interpretation - N.L., Literature Review - B.S.I.., Writer - N.L., Critical Review-B.S.I.

Conflict of Interest: No conflict of interest was declared by the authors.

Financial Disclosure: The authors declared that this study has received no financial support.

\section{References}

1. Şimșek Kaya G, Daltaban Ö, Kaya M, Kocabalkan B, Sindel A, Akdağ M. The potential clinical relevance of anatomical structures and variations of the maxillary sinus for planned sinus floor elevation procedures: A retrospective cone beam computed tomography study. Clin Implant Dent Related Res 2019;21(1):114-21. (Crossref)

2. Starch-Jensen $T$, Aludden H, Hallman M, Dahlin C, Christensen $\mathrm{AE}$, Mordenfeld A. A systematic review and meta-analysis of long-term studies (five or more years) assessing maxillary sinus floor augmenta- tion. Int J Oral Maxillofac Surg 2017;47: 10316. (Crossref)

3. Vazquez JCM, de Rivera ASG, Gil HS, Mifsut RS. Complication rate in 200 consecutive sinus lift procedures: guidelines for prevention and treatment. J Oral Maxillofac Surg 2014;72: 892901. (Crossref)

4. Bornstein MM, Seiffert C, Maestre-Ferrín L, et al. An analysis of fre- quency, morphology, and locations of maxillary sinus septa using cone beam computed tomography. Int J Oral Maxillofac Implants 2016;31: 280-7. (Crossref)

5. Jung J, Yim JH, Kwon YD, et al. A radiographic study of the position and prevalence of the maxillary arterial endosseous anastomosis using cone beam computed tomography. Int J Oral Maxillofac Implants 2011;26:1273-8.

6. Rancitelli D, Borgonovo AE, Cicciu M, et al. Maxillary sinus septa and anatomic correlation with the Schneiderian membrane. J Craniofac Surg 2015;26:1394-8. (Crossref)

7. Maestre-Ferrin L, Galan-Gil S, Rubio-Serrano M, PenarrochaDiago M, Penarrocha-Oltra D. Maxillary sinus septa: a systematic review. Med Oral Patol Oral Cir Bucal 2010;15: e3836. (Crossref)

8. Hungerbühler A, Rostetter C, Lübbers HT, Rücker $M$, Stadlinger B. Anatomical characteristics of maxillary sinus septa visualized by cone beam computed tomography. Int J Oral Maxillofac Surg 2019;48(3): 382-7. (Crossref)

9. Dragan E, Odri GA, Melian G, Haba D, Olszewski R. Threedimensional evaluation of maxillary sinus septa for implant placement. Med Sci Monit. 2017;23: 1394-1400. (Crossref)

10. Velasquez-Plata D, Hovey LR, Peach CC, Alder ME. Maxillary sinus septa: A 3-dimensional computerized tomographic scan analysis. Int J Oral Maxillofac Implants 2002;17: 854-60.

11. Orhan K, Kusakci Seker B, Aksoy S, Bayindir H, Berberoğlu A, Seker E. Cone beam CT evaluation of maxillary sinus septa prevalence, height, location and morphology in children and an adult population. Med Princ Pract 2013;22(1): 47-53. (Crossref) 
12. Goga D1, Romieux G, Bonin B, Picard A, Saffarzadeh A. Preimplantation iliac graft in the sinus. Retrospective study of the complications encountered in 100 cases. Rev Stomatol Chir Maxillofac 2000;101(6): 303-8.

13. Cangul S, Adiguzel O. Cone-Beam Three-Dimensional Dental Volumetric Tomography in Dental Practice. Int Dent Res 2017;7:62-70. (Crossref)

14. Aktuna Belgin $C$, Adiguzel $O$, Bud $M$, Colak M, Akkus $Z$. Mandibular Buccal Bone Thickness In Southeastern Anatolian People: A Cone-Beam Computed Tomography Study. Int Dent Res 2017;7:6-12. (Crossref)

15. Laçin N, Aytuğar E, Veli i. Cone-beam computed tomography evaluation of bifid mandibular canal. Int Dent Res 2018;8(2):7883. (Crossref)

16. Laçin N, Tatar B, Veli I, Adıgüzel A. Evaluation of medial lingual foramen with cone-beam computed tomography in a Turkish adult population. Int Dent Res 2018;8(3):139-43. (Crossref)

17. Falakaloglu $S$, Veis $A$. Determining the size of the mental foramen: A cone-beam computed tomography study. Int Dent Res 2017;7:20-25. (Crossref)

18. Açıklar Kavas A, Tümen EC. Volumetric pulp chambers measurements in mandibular and maxillary permanent first molar using cone-beam computed tomography by age and gender. Int Dent Res 2019;9(1):30-40. (Crossref)

19. Adiguzel O, Aktuna Belgin C, Falakaloglu S, Cangul S, Akkus S. Maxillary Cortical Bone Thickness in a South-Eastern Anatolian Population: A Cone-Beam Computed Tomography Study. Med Sci Monit 2017;23:5812-7. (Crossref)
20. Jang SY, Chung K, Jung S, Park HJ, Oh HK, Kook MS. Comparative study of the sinus septa between dentulous and edentulous patients by cone beam computed tomography. Implant Dent 2014; 23(4): 477-81. (Crossref)

21. Sakhdari S, Panjnoush M, Eyvazlou A, Niktash A. Determination of the Prevalence, Height, and Location of the Maxillary Sinus Septa Using Cone Beam Computed Tomography. Implant Dent 2016; 25(3): 335-40. (Crossref)

22. Talo Yildirim T, Güncü GN, Colak $M$, Nares $S$, Tözüm TF. Evaluation of maxillary sinus septa: a retrospective clinical study with cone beam computerized tomography (CBCT). Eur Rev Med Pharmacol Sci 2017; 21(23): 5306-14.

23. Lee WJ, Lee SJ, Kim HS. Analysis of location and prevalence of maxillary sinus septa. J Periodontal Implant Sci 2010; 40: 56 60. (Crossref)

24. Uner DD, Izol BS, Ipek F. The evaluation of the prevalence and localizations and of antral septa in people living in and around Diyarbakir using cone beam computed tomography. Journal of Oral and Maxillofacial Radiology 2018;6(1):3-8. (Crossref)

25. Chanavaz M. Maxillary sinus: Anatomy, physiology, surgery, and bone grafting related to implantology-eleven years of surgical experience. J Oral Implantol 1990;16: 199-209.

26. Schriber $M$, von Arx T, Sendi P, Jacobs R, Suter VG, Bornstein $M M$. Evaluating maxillary sinus septa using cone beam computed tomography: is there a difference in frequency and type between the dentate and edentulous posterior maxilla. Int J Oral Maxillofac Implants 2017; 32(6):1324-32. (Crossref) 